Discussion Paper No. 13-108

\title{
Return and Risk of Human Capital Contracts
}

Tim A. Kroencke, Grit Muehler, and Maresa Sprietsma

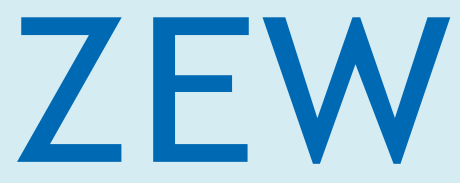

Zentrum für Europäische Wirtschaftsforschung $\mathrm{GmbH}$

Centre for European Economic Research 
Discussion Paper No. 13-108

\title{
Return and Risk of Human Capital Contracts
}

\author{
Tim A. Kroencke, Grit Muehler, \\ and Maresa Sprietsma
}

Download this ZEW Discussion Paper from our ftp server:

http://ftp.zew.de/pub/zew-docs/dp/dp13108.pdf

Die Discussion Papers dienen einer möglichst schnellen Verbreitung von neueren Forschungsarbeiten des ZEW. Die Beiträge liegen in alleiniger Verantwortung der Autoren und stellen nicht notwendigerweise die Meinung des ZEW dar.

Discussion Papers are intended to make results of ZEW research promptly available to other economists in order to encourage discussion and suggestions for revisions. The authors are solely responsible for the contents which do not necessarily represent the opinion of the ZEW. 


\title{
Heturn and Risk of
}

\author{
Tim A. Kroencke Grit Muehler Maresa Sprietsma
}

December 10, 2013

\begin{abstract}
Human capital contracts give private investors the right to a share of students' future earnings in return for a financial contribution during their studies. Although still rarely used, human capital contracts could not only help to complement limited public funding for higher education but might also be an alternative to traditional financial assets. Using a dataset covering $1 \%$ of German households for the period 1995-2009, we analyse the return and risk properties that can be expected from human capital contracts. We find that funds of human capital contracts provide low risk exposures to stocks and bonds. As a result, risk-adjusted returns of funds of human capital contracts are significantly positive under fairly weak conditions. Thus, human capital contracts potentially offer large diversification benefits for investors and might be a way to improve the state's educational budget.
\end{abstract}

JEL-Classification: I21, J24, G11, G12

Keywords: human capital returns, human capital contracts, risk and return of non-traded assets, mean-variance spanning tests.

\footnotetext{
*Kroencke: University of Mannheim. Muehler: ZEW Mannheim. Sprietsma (corresponding author): ZEW Mannheim, sprietsma@zew.de. We thank Adam Booij, Sebastian Butschek, Miguel Palacios, Felix Schindler, Peter Westerheide, and participants at the SEEK workshop "Private funding of tertiary education - Human capital as an asset class" for helpful comments and discussion. We are also grateful to Joost Driessen, Tse-Chun Lin, and Ludovic Phalippou for help with their GMM estimator. Financial support within the scope of the research programme "Strengthening Efficiency and Competitiveness in the European Knowledge Economies" (SEEK) is gratefully acknowledged.
} 


\section{Introduction}

While there is the political will to invest more in higher education and to increase the number of graduates (Council of the European Union, 2009), public financing of tertiary education has come under pressure. In effect, the growing demand for tertiary education is accompanied by increased expenditure on public pensions, health care or early childhood education as well as the financial burden of the recent financial crisis. Boosting private contributions to tertiary education may be one way to help to alleviate limited public budgets.

Private expenditure on tertiary education has indeed increased strongly in the past decade, even in countries with a low initial private share in the funding of tertiary education. While public expenditures for tertiary education in OECD countries rose by 27 percent from 2000 to 2007 on average, private expenditure doubled (see OECD (2010), Table B3.2b). In Germany, public support of students was reformed over the last years. Grants (Bafög) were replaced partly by student loans and since 2010, students have to repay half of the received public support after graduation.

In addition, the oncoming shortage of qualified labor in combination with a relative abundance of the factor capital could lead to a decrease in the average rate of return to capital investment by around 90 basis points until 2050 (Ludwig, Krueger, and Boersch-Supan, 2007). Even though this is only a rough estimate, derived from a highly aggregated macroeconomic model, it shows that the ratio of wages to capital incomes is likely to increase considerably in the long run. As a result, investors seeking to stabilize their yields may be interested in alternative assets, in particular investments in human capital.

In this paper, we study the return and risk properties of hypothetical human capital contracts. These are equity-like instruments allowing direct investment in human capital. A typical human capital contract is designed as follows: an investor pays students a yearly or monthly annuity for the duration of their studies. After graduation, the students pay the investor a fixed share of their income for a certain period. Depending on the achieved income, students may end up paying back more or less than the amount initially 
received. The financial return on a human capital contract depends both on the time of reimbursement and on the share of income payable to the investor.

Human capital contracts as a way of securing private funding of higher education were already advocated by Friedman (1955). And although the concept of human capital contracts has spread in recent years, so far there have been only a limited number of attempts to implement human capital contracts in real life (see e.g. Palacios (2004)). ${ }^{1}$ Yet, from an economic perspective, the market for human capital contracts might be huge. Lustig, van Nieuwerburgh, and Verdelhan (2013) estimate that the human capital share of total wealth is as large as $90 \%$, whereas equity only contributes $2 \%$. Put differently, if only $2.07 \%$ of human capital were eventually investable, in the form of human capital contracts, this market would be bigger than the common stock market. In this light, human capital contracts as equity-like instruments are a promising alternative to traditional financial assets. Our analysis serves as a first empirical evaluation of their return and risk properties.

We compute the return and risk properties of human capital contracts using the German census for the period from 1995 to 2009. For each graduation vintage year, we derive the cash flow to hypothetical funds of human capital contracts, and compute their abnormal return ("alpha") and risk exposures ("betas") to common stocks and government bonds. To this end, we apply a novel GMM estimator proposed by Driessen, Lin, and Phalippou (2012), which makes it possible to estimate return and risk characteristics of non-traded assets based on their cash flows.

Our paper contributes to the existing literature in several respects. First, we replicate and complement the analysis of Palacios-Huerta (2003), who assesses the value-added of including human capital into a financial portfolio using US data. Based on traditional mean-variance spanning tests (Huberman and Kandel (1987), Bekaert and Urias (1996)), he finds that human capital would make a highly valuable complement to a financial

\footnotetext{
${ }^{1}$ Suppliers of human capital contracts in Germany include Deutsche Bildung, and CareerConcept, and for America Lumni and Pave (see also "Start me up - crowdfunding students" available in the print edition of "The Economist", June 15th 2013). Palacios (2004) provides a comprehensive overview on human capital contracts, also covering challenges real life funds of human capital contracts face and how these can be overcome.
} 
portfolio. $^{2}$ Our paper provides an improvement to the literature with respect to the empirical design of the mean-variance spanning tests for human capital as we apply a modification of the mean-variance spanning test, which takes market frictions in the form of short sales constraints into account. This short sales restricted test was proposed by DeRoon, Nijman, and Werker (2001) and was not used in Palacios-Huerta (2003).

Second, while our methodology to evaluate return and risk properties of human capital contracts is consistent with mean-variance spanning tests, we base our analysis on cash flows investors can realistically receive from human capital contracts. Previous studies rely on measures based on labor income growth as a proxy of the return on human capital (e.g. Fama and Schwert (1977), Becker (1993), Campbell (1996), Jagannathan and Wang (1996), Palacios-Huerta (2003)). Using these measures in our context would imply that the total amount of returns to education is considered to flow back into the fund whereas in practice only a share of net income after graduation can flow into the fund. Moreover, in contrast to our analysis, default risk is not taken into account in Palacios-Huerta (2003) as only full-time workers are included and no cap on reimbursement or years of repayment are considered.

We find that the risk exposures to stocks and bonds of human capital contracts are close to zero. Consequently, the estimated alphas are significantly positive using conservative assumptions, which means that students have to share only a modest amount of their income with funds of human capital contracts. Our results are noteworthy in particular compared to those reported in the literature for traditional and alternative investments in physical capital. For the aggregate market of mutual stock funds, Fama and French (2010) find alphas close to zero (before fees) and stock market betas of one. Driessen, Lin, and Phalippou (2012) even report negative alphas and stock market betas of 1.5 (2.9) for non-traded private equity funds (venture capital).

The paper is structured as follows. The next section presents the data, followed by a

\footnotetext{
${ }^{2}$ Similarly, Fama and Schwert (1977) find that the return on human capital does not improve the capital asset pricing model of Sharpe (1964) and Lintner (1965), since their correlation with various financial assets is weak. Jagannathan and Wang (1996) and Eiling (2013) find stronger correlations using a different timing or industry specific labor income as a proxy for the return on human capital.
} 
mean-variance spanning analysis as in Palacios-Huerta (2003) for our data in Section 3. In Section 4 we present our approach to measuring the performance of human capital contracts. Section 5 reports the baseline results of the return and risk estimates of human capital contracts and presents results when specific conditions of human capital contracts are varied, and Section 6 concludes.

\section{Data}

We use the German Mikrocensus for the years 1995-2009, a yearly representative survey dataset including $1 \%$ of all German households. This represents about 380,000 households with 820,000 individuals. The data is a repeated cross-section and, amongst others, contains information on income, and experience as well as on education and employment status. We restrict the sample by excluding soldiers, self-employed workers, workers that participate in dual vocational education as well as school pupils, students, retired individuals, individuals under age 15 as well as individuals over age 55. Individuals with a recognized disability are also excluded. We consider both a restricted sample of only full-time workers in order to ensure comparability with Palacios-Huerta (2003), and the full sample including unemployed and part-time workers.

The main variable of interest is the monthly net income. This includes the wage but also unemployment benefits, and financial assistance from the state or the family if applicable (in the full sample). The monthly net income is measured in a given month of the year: in April until 2003, in March in 2004 and in the month before the survey date (that we observe) from 2005 onwards.

For our mean-variance spanning tests in the the spirit of Palacios-Huerta (2003), we distinguish three experience categories (3,6 and 9 years of experience) to be able to compare our results. The highest educational degree is classified into 4 categories: none or up to a secondary school degree, a degree from 3-4 years of vocational training ("duale Ausbildung", equivalent to ISCED category 3B), a degree from an additional 1-2 years of advanced vocational training ("Meister, Techniker", equivalent to ISCED 5B) and a degree 
from tertiary education (university or university of applied sciences, equivalent to ISCED $5 \mathrm{~A}$ (or higher)). For all other analyses we measure experience in years $(1,2,3, \ldots 10$ years of experience) and restrict the sample to those individuals with a higher educational degree (tertiary education). Yearly information on education is available only from 1995 onwards.

\section{Human Capital as an Asset Class}

In this section, we evaluate the stochastic properties of human capital returns in Germany with mean-variance spanning tests as in Palacios-Huerta (2003). We then discuss how our measure of returns on human capital contracts differs from Palacios-Huerta's measure of human capital returns.

Mean-variance spanning tests consist of analyzing the effects of introducing an additional asset to the investment opportunity set on a portfolio of benchmark assets on the meanvariance frontier. In this sense, human capital investments constitute an improvement of the portfolio performance if there is an increase in the expected return per unit of risk when human capital is included in the portfolio of benchmark assets.

In Palacios-Huerta (2003), the utility from the discounted future gains from education is equal to the utility of today's wage:

$$
w_{e-1, t}=E_{t}\left(m_{t+1} w_{e, t+1}\right)
$$

where $m_{t+1}=\beta u^{\prime}\left(c_{t+1}\right) / u^{\prime}\left(c_{t}\right)$ is the intertemporal marginal rate of substitution (IMRS), and $w_{e, t+1}$ is the wage when holding $e$ units of education at time $t+1$. Thus, defining $R_{e, t+1}^{h}=w_{e, t+1} / w_{e-1, t}$ as the marginal return to education leads to the central pricing formula in finance (Cochrane (2005), Chapter 1): ${ }^{3}$

\footnotetext{
${ }^{3}$ Palacios-Huerta (2003) is the first using this kind of measure. In Footnote 4 of his paper, it is acknowledged that this measure goes back to a suggestion by Kevin M. Murphy.
} 


$$
1=E_{t}\left(m_{t+1} R_{e, t+1}^{h}\right)
$$

where the equation becomes an inequality in the presence of market frictions such as shortsales constraints (e.g. He and Modest (1995), Luttmer (1996)). Asset pricing models differ in the exact specification of the IMRS, $m_{t+1}$. Palacios-Huerta (2003) considers mean-variance spanning tests which can be derived from a particular parametrization of the IMRS, as described below.

It is well known that a set of benchmark assets span the mean-variance frontier if they are able to price the test asset correctly (e.g. Hansen and Jagannathan (1991), Bekaert and Urias (1996)), that is, the IMRS

$$
m_{t+1}^{*}\left(v, \mathbf{R}_{t+1}\right)=v+\mathbf{b}^{\prime}\left(\mathbf{R}_{t+1}-E\left(\mathbf{R}_{t+1}\right)\right),
$$

satisfies Equation (2), where $\mathbf{R}_{t+1}$ is a vector of $\mathrm{N}$ benchmark asset returns (e.g. stocks and bonds) and $\mathbf{b}$ is a vector of coefficients defined in the Appendix. The intuition is that if Equation (9) holds, all pricing relevant information is carried by the benchmark assets. Put differently, the stochastic properties of the test assets can be fully replicated from the benchmark assets and an investor cannot gain by investing in the test assets beyond the gains available from the benchmark assets. If $v$ is set to $1 /\left(1+r_{f}\right)$, the inverse of the risk-free rate, Equation (2) implies a beta asset pricing representation:

$$
R_{e, t+1}^{h}-r_{f}=\alpha+\boldsymbol{\beta}\left(\mathbf{R}_{\mathbf{t}+\mathbf{1}}-r_{f} \mathbf{1}_{N}\right)+\varepsilon_{t+1}
$$

with the testable condition $\alpha=0$ for mean-variance spanning (see Huberman and Kandel (1987), Bekaert and Urias (1996), DeRoon and Nijman (2001)). The beta pricing representation offers an intuitive economic interpretation as well. Positive alphas imply that this component of the return cannot be replicated by the benchmark assets and the investor will want to add the test asset (e.g. human capital) to their portfolio. Contrary, negative alphas indicate that the investor should take short positions in the test 
asset. Further technical details are provided in the Appendix, which also covers a test for mean-variance spanning with short sales constraints as proposed by DeRoon, Nijman, and Werker (2001).

We provide results on mean-variance spanning tests in Table 1 in order to assess the relevance of human capital in a portfolio context for the German market. To make our analysis comparable with that of Palacios-Huerta (2003), we compute human capital returns by gender, the level of education and experience. We distinguish three levels of experience and include only full-time workers. The details on how we calculate $R_{e, t+1}^{h}$ from our data are reported in the Appendix. The benchmark assets are returns on European stocks and ten year German government bonds. ${ }^{4}$ Besides the Wald test (HK) proposed by Huberman and Kandel (1987), we compute a modification of the mean-variance spanning test that explicitly takes short sale restrictions for human capital into account (DNW), as suggested by DeRoon, Nijman, and Werker (2001). Furthermore, we report direct estimates of alpha.

- Insert TABLE 1 about here -

In our mean-variance spanning analysis for Germany, we find similar results as PalaciosHuerta (2003) finds for the US. As in the US, higher education constitutes a valuable improvement for financial portfolios. Alphas of human capital at the level of university degrees are in the range between $7.2 \%$ and $10 \%$ p.a. The HK-test statistics as well as the DNW-test statistics indicate a significant portfolio improvement from adding human capital to a portfolio of stocks and bonds. In contrast, for low educational levels, alphas are (slightly) negative indicating the absence of diversification benefits if short sales are not available. We find that the HK-test often falsely indicates significant benefits, since this test does not take short-sale constraints into account. ${ }^{5}$ The DNW-test - which accounts for short-sales constraints - allows us to draw the same conclusion as from estimtated alphas in all the cases we consider.

\footnotetext{
${ }^{4}$ European stocks are proxied by the MSCI Europe total return index and German government bonds by the BofA Merrill Lynch German Government bonds (7-10y) total return index, both available via Thomson Reuters Datastream.

${ }^{5}$ The likelihood-ratio test counterpart of these test statistics is used in Palacios-Huerta (2003).
} 
The return measure used in the mean-variance spanning analysis above is the marginal return to education for the individual, and is likely to overestimate the returns to human capital available to concrete investment vehicles like human capital contracts. Firstly, the cash flow implied by the measure of the return on human capital, i.e. paying $w_{e-1, t}$ in $t$ and receiving $w_{e, t+1}$ in $t+1$, is not achievable for investment vehicles. Secondly, investment vehicles like human capital contracts are constructed such that only a fraction of the return to education (typically between $5 \%$ and $10 \%$ of gross wage) flows back to the fund. Thus, even though $R_{e, t+1}^{h}$ is highly correlated with the return of human capital contracts, it is not clear if a significant amount of the returns arrives at the fund level under realistic assumptions. Finally, only full-time workers are taken into account, thereby ignoring the risk of default in case of unemployment, non-participation in the labor market or part-time employment.

In the next section, we compute cash flows of human capital contracts that funds can realistically generate. Based on these cash flows, we calculate the abnormal return and risk exposures of human capital contracts, relying on a methodology consistent with the mean-variance spanning framework. Our main question is whether the shifts in the meanvariance efficiency frontier are robust to this transformation of the returns on investment in higher education.

\section{Return and Risk of Human Capital Contracts}

Human capital contracts (HCC) are one possible instrument of including human capital into a financial portfolio. Investors give a certain number of students a yearly or monthly amount of money for the duration of their studies. These students together constitute a human capital fund for the investor. After graduation, these students pay a fixed share of their net income to the investor for a fixed amount of time. Depending on the achieved income, students may end up paying back more or less than the amount initially received. The financial return to a human capital fund depends on the time of reimbursement as well as on the share of net income that is to be paid into the fund by the students. 


\subsection{Measuring the Performance of Human Capital Contracts}

In order to assess the financial performance of human capital contracts, we compute their internal rate of return (IRR), abnormal return (alpha), and the risk exposures to the stock and bond markets (betas). The abnormal return cannot be replicated using investments in stocks and bonds and is therefore particularly relevant to an investor. It is a measure of the diversification benefits of the asset to be tested (human capital contracts) against a portfolio of benchmark assets (bonds and stocks). We cannot directly use Equation (4) to estimate alphas and betas of human capital contracts since we only observe cash flows but not market returns. Instead, we rely on an indirect method proposed by Driessen, Lin, and Phalippou (2012) to infer alphas and betas from cash flows.

The internal rate of return of the cash flow stream of human capital fund $i=1, \ldots, I$ is computed by solving

$$
\sum_{t=t_{0 i}}^{L_{i}}\left[\frac{D_{i t}-T_{i t}}{\left(1+I R R_{i}\right)^{t-t_{0 i}}}\right]=N P V=0,
$$

where $t_{0 i}$ and $L_{i}$ are the start and the end date of the $\mathrm{HCC}, D_{i t}$ are the repayments (dividends), and $T_{i t}$ are the investments. NPV stands for the net present value of the investment. Driessen, Lin, and Phalippou (2012) extend the standard approach of IRR calculation by accounting for risk exposures. Instead of being constant, the discount rate is allowed to vary over time. In our application it is equal to $1+r_{f, t}+\alpha+\beta_{S} r_{S t o c k s, t}+$ $\beta_{B} r_{B o n d s, t}$, where $r_{f, t}$ is the risk-free rate, $r_{S t o c k s, t}$ is the excess stock market return, and $r_{B o n d s, t}$ is the excess bond market return. The coefficients $\alpha$ and $\beta=\left[\beta_{S}, \beta_{B}\right]$ are assumed to be identical for the I portfolios and are the parameters to be estimated.

Driessen, Lin, and Phalippou (2012) propose estimating $\alpha$ and $\beta$ by solving the least squares optimization

$$
\min _{\alpha, \beta}=\sum_{i=1}^{I}\left[N P V_{i}(\alpha, \beta)\right]^{2}
$$


where

$$
N P V_{i}(\alpha, \beta)=\sum_{t=t_{0 i}}^{L_{i}}\left[\frac{D_{i t}-T_{i t}}{\prod_{s=t_{0 i}+1}^{t}\left(1+r_{f, t}+\alpha+\beta_{S} r_{S, t}+\beta_{B} r_{B, t}\right)}\right]
$$

The basic idea of this estimator is to exploit the cross-section of portfolio net-present values to identify the coefficients $\alpha$ and $\beta$. Driessen, Lin, and Phalippou (2012) show that this estimator can be written as an asymptotically consistent GMM estimator and provide numerical examples as well as a comprehensive simulation study.

This method for estimating risk-adjusted returns is consistent with the mean-variance spanning tests in the previous section and Palacios-Huerta (2003). Importantly, this procedure allows us to base our estimates directly on cash flows that investors can realistically

expect rather than on a return measure such as $R_{e, t+1}^{h}$. As discussed above, the latter bases on assumptions that are unlikely to hold in practice.

\subsection{Human Capital Contract Conditions}

We transform the wage distribution into a cash flow distribution for human capital contracts by weighted re-sampling. The transformation function leaves some room for a number of different calibrations. Below we outline the characteristics of our baseline fund of human capital contracts. The robustness section of this paper covers a scenario analysis illustrating the sensitivity of the results to each of the different characteristics of the HCC. We define our fund of human capital contracts as follows:

- In the investment phase the fund pays each student 8,000 Euros per year (deflated by the 2009 consumer price index) for three years. This corresponds to the maximum amount of public support for students from low-income families in Germany. This amount is intended to cover living expenses for the duration of studies (college attendance itself is free in Germany).

- In the repayment phase, starting with the first job after graduation, each student $n$ 
pays $D_{n t}=\theta \times$ income $_{n t}$ to the fund for the following nine years, where income $_{n t}$ corresponds to net earnings after tax and social insurance.

- We consider repayments to the fund $\theta$ in the range between 10 and 20 percent of net income. This corresponds to approximately 5 to 10 percent of gross earnings, rates that are observed for existing funds.

- Unemployed individuals, those on social assistance or those on parental leave do not make repayments into the fund.

- Each fund invests in one cohort of students. Tracking the cash flows of a specific fund is equivalent to tracking the labour market performance of a specific cohort of students. The first fund starts investing in 1992 and receives repayments starting in 1995, ending in 2003. The cash flows of the second fund span the period 1993 to 2004. The cash flows of the seventh (and last) fund spans the period from 1998 to 2009. That is, we track a total of seven vintage years of students (seven funds) covering a period of 18 years (1992-2009).

- We simulate human capital funds made up of 50 randomly chosen male and 50 randomly chosen female students.

For each fund we compute cash flows based on reported earnings and the transformation function outlined above. Based on the resulting cash flow matrix for the seven vintage funds, we compute internal rate of returns, alphas, and betas. We repeat this procedure 1,000 times to allow for inference on return and risk estimates.

Figure 1 shows the average earnings of cohorts of 50 male and 50 female graduates averaged across the 1,000 simulations. We find earnings of the cohorts to increase by around 7,5\% per year of experience for males, and by $5 \%$ per year of experience for females.

- Insert FIGURE 1 about here -

Table 2 illustrates the funds' cash flows per student averaged across the 1,000 simulations. In the first three years, cash flows are negative because the fund allocates money to 
finance the students' higher education. The nine years after graduation have positive and increasing cash flows as the students' incomes increase over time. We find that the cross-sectional and time-series variation of earnings carries over to the fund cash flows. Figure 1 and Table 2 are based on the sample including only full-time workers.

\section{- Insert TABLE 2 about here -}

Our analysis involves several simplifications due to the limitations of our data. First of all, we assume that no student drops out of higher education. In practice, HCC include a clause stipulating that in the case of dropout, the contract automatically becomes a loan. This allows the fund to at least recover the invested amount. As a result, the impact of student dropout on cash flows can safely be ignored. Secondly, all students are assumed to complete their studies after three years. This will bias estimated returns upwards since delays in repayment due to a longer time until graduation are not taken into account. However, the students in the fund have a strong incentive to graduate before their funding runs out. Moreover, in contrast to existing human capital funds in Germany, our fund does not impose minimum grade requirements or other selection procedures. This will bias the estimated returns downwards.

\section{Empirical Results}

In this section, we present our estimates of the performance of the hypothetical human capital funds outlined above. We first compute the risk and returns of HCC using a sample where only full-time workers are included. Results for the full-time workers sample are directly comparable to the Palacios-Huerta (2003) results. In a second analysis, we enlarge the sample to include part-time workers and individuals with no labor income. This introduces a default risk since these persons do not make repayments into the fund. Including part-time workers also reduces returns in that earnings are lower for this group, making our analysis more realistic from the perspective of an investor. In a final step we 
perform a series of robustness checks by changing the duration of repayment, introducing caps on the repayments and varying the number of students in a fund.

\subsection{Full-Time Workers}

Panel A of Table 3 gives the IRRs, alphas, and betas for our human capital fund when only full-time workers are included. We consider a range of different values for the share of net income $(\theta)$ that is re-payed to the fund $\theta=\{10 \%, 12.5 \%, 15 \%, 17.5 \%, 20 \%\}$.

- Insert TABLE 3 about here -

We find that IRRs and abnormal returns $\alpha$ vary significantly with the share of net income that is paid to the fund. The abnormal return is positive for shares of reimbursement equal or larger than $12.5 \%$ of net income. The point estimates for the stock market beta and the bond market beta are close to zero, or even slightly negative. This means that there is little correlation between returns to education and returns on bonds or stocks. The low level of systematic risk implies that HCC offer high potential diversification benefits, even if the share of reimbursement is relatively modest.

We find that confidence intervals for bond market betas are about five times larger than for stock market betas. This implies that investing in human capital as a complement to a portfolio of stocks is a good asset diversification strategy with high certainty. This remains more uncertain for portfolios of bonds.

Figure 2 illustrates this point visually and shows the sum of net present values (see Equation (6)) as a function of the parameters to be estimated. Since stock and bond market correlation is low, we estimate the univariate version of Equation (6) for the average cash flow matrix across all simulations. The stock market is the only risk factor in the upper part of the figure, and the bond market is the only risk factor in the lower part of the figure. As indicated by the bootstrapped confidence intervals in Table 3, the value function is flat along the dimension of the bond market beta. In contrast, the value function is steep with respect to the alpha and the stock market beta. 


\subsection{Default Risk}

Results on full-time workers overstate the likely cash flows of human capital funds because there is no default risk. We therefore also provide results for a broader sample that includes unemployed individuals, individuals on parental leave, individuals dependant on family or state support and part-time workers. These groups of people do not generate cash flows to the fund. Figure 3 illustrates the default risk posed by non-performing human capital contracts. It shows the fraction of workers who have no labor income in the extended sample. We observe that the resulting risk of default is very limited as the default rate lies below 10 percent in our sample over the time period considered.

- Insert FIGURE 3 about here -

Panel B of Table 3 presents IRRs, alphas, and betas for the human capital fund defined in Section 4.2. using the extended sample of graduates. It shows the performance of our human capital fund when taking into account the default risk arising from unemployment and from non-participation in the labor market. As for the restricted sample of fulltime workers, stock and bond market betas of funds of human capital contracts are close to zero. The internal rate of return is $2 \%$ lower in the extended sample (on average), abnormal performance decreases by half but remains positive for values of $\theta$ of $15 \%$ and higher. Therefore, even when default risk is taken into account, the performance of HCC remains economically significant under realistic repayment conditions.

\subsection{Robustness of Results}

In addition to our analysis based on different samples of graduates we perform robustness tests by modifying the conditions of the human capital contracts (Tables 4 and 5). First, we include a cap on repayments such that individuals are left with a net income of at least 
1,300 Euros after making repayments to the fund. ${ }^{6}$ Second, we modify the idiosyncratic risk of funds of human capital contracts by varying the number of $\mathrm{HCC}$ in a fund. Third, we compute results for different durations of repayment: results are presented for 8 and 10 repayment years.

- Insert TABLE 4 about here -

- Insert TABLE 5 about here -

Introducing a repayment cap similar to that in place for public student loans reduces abnormal performance by nearly half but it remains significantly positive for values of $\theta$ of $15 \%$ and higher. Modifying the size of the human capital portfolio does not affect its performance. However, confidence intervals on abnormal performance for the small funds we simulate are approximately one percentage point larger than for the large funds.

The duration of the repayment period is very relevant for the performance of the human capital fund. Shortening the repayment period to eight instead of nine years reduces the performance of the human capital fund in a similar way as the inclusion of default risk. Abnormal performance is reduced by half and positive for $\theta$ of $15 \%$ and higher.

A HCC including graduates that do not generate cash flows to the fund because of unemployment or non-participation to the labor market and capping repayment so that 1,300 Euro remain with the graduate decreases abnormal performance by half when compared with the sample including all graduates but without a cap on repayment. Moreover, the abnormal performance is positive only for $\theta$ of $17.5 \%$ and higher.

In short, we find that funds of human capital contracts offer a promising investment performance, even for a random sample of graduates including unemployed and part-time workers. Our estimates on abnormal returns of HCC are considerably lower than the returns to human capital found in Palacios-Huerta (2003) and are affected downwards by less favorable conditions for the investor. Overall they remain large enough to indicate

\footnotetext{
${ }^{6}$ In Germany, income below 1300 Euro per month is exempt from execution. That is, when a debtor defaults, his creditor cannot claim income under this threshold.
} 
significant diversification benefits of human capital for financial portfolios even under conditions that are less favorable for the investor.

\section{Conclusion}

In this paper we assessed the return and risk performance of funds of human capital contracts from the point of view of an investor. Our estimates are based on a novel GMM estimator proposed by Driessen, Lin, and Phalippou (2012), which makes it possible to calculate return and risk properties of non-traded assets using their cash flows. We find that funds of human capital contracts have very low risk exposures to stock and bond markets and generate positive abnormal returns under rather conservative assumptions. These characteristics compare favorably with those of mutual funds and private equity, which show high risk exposures and zero or negative abnormal returns.

The performance of human capital funds depends on the time of reimbursement and on the share of net income to be paid back to the fund. Even if we assume conditions of reimbursement that are less favorable for the investor and take into account default risk, we find a reasonable performance of our human capital funds (though lower than predicted in Palacios-Huerta (2003)). Including a cap on the repayments students have to make, considering funds of human capital contracts with more or less idiosyncratic risk and shorter times of reimbursement, we find that our estimates of risk exposures are unaffected, and estimates of abnormal decrease by half. Our results indicate potentially large diversification benefits for stock and bond investors who consider to add funds of human capital contracts to their portfolio.

Issuing human capital contracts may also be a way for the state to provide additional student support. By boosting public educational budgets through their high returns, they might help to internalise some of the returns to the extensive human capital investments made by European governments. 


\section{Appendix}

\section{A Details on Mean-Variance Spanning Tests}

Measuring human capital returns. An important empirical issue in when computing $R_{e, t+1}^{h}$ is how to link the data on $w_{e-1, t}$ and $w_{e, t+1}$ in a sensible way. Palacios-Huerta (2003) assumes that the level of education $e$ corresponds to years of education. However, as in Palacios-Huerta (2003), we do not observe the actual years of education but the attainment of specific levels of qualification such as secondary school, vocational training ("Lehre"), advanced vocational training ("Meister"), or university. To calculate the marginal return from an additional year of education, we use the following approximation for the wage $e-1$ :

$$
w_{e-1, t}=w_{e-g, t}+\left(w_{e, t}-w_{e-g, t}\right) \frac{y_{e}-y_{e-g}-1}{y_{e}-y_{e-g}},
$$

where $y_{e}$ is the minimum number of years of education necessary to reach education level $e$, and $y_{e-g}$ is the number of years of education necessary to reach the level of qualification just below. In order to ensure comparability with Palacios-Huerta (2003), we use $y_{e}=11$ for a secondary school degree, $y_{e}=14$ for a vocational training ("Lehre"), $y_{e}=16$ for an advanced vocational training ("Meister"), and $y_{e}=18$ for a university degree. ${ }^{7}$ These values correspond roughly to the years of schooling needed to achieve these qualification levels in Germany. As a result, we set $y_{e-g}=11$ for secondary school, $y_{e-g}=11$ for vocational training ("Lehre"), and $y_{e-g}=14$ for advanced vocational training ("Meister") and university degrees.

\footnotetext{
${ }^{7}$ Unfortunately, Palacios-Huerta (2003) does not provide details on how he handles this issue. However, in an earlier working paper version it is assumed that $e=10$ for "some high school", $e=12$ for "high school graduates", $e=14$ for some college", $e=16$ for "college graduates", and $e=18$ for for "more than college" (Palacios-Huerta (1997)).
} 
Mean-variance spanning tests. We say that a K-dimensional vector of $\mathbf{R}_{t+1}$ benchmark assets spans an N-dimensional vector $\mathbf{r}_{t+1}$ of test asset returns if the candidate IMRS $m_{t+1}^{*}$ solves the pricing equation

$$
E\left(m_{t+1}^{*}\left(v, \mathbf{R}_{t+1}\right) \mathbf{r}_{t+1}\right)=\mathbf{1}_{N}
$$

where $m_{t+1}^{*}\left(v, \mathbf{R}_{t+1}\right)=v+\mathbf{b}^{\prime}\left(\mathbf{R}_{t+1}-E\left(\mathbf{R}_{t+1}\right)\right)$ satisfies the pricing equation for the $\mathrm{K}$ benchmark assets, $E\left(m_{t+1}^{*} \mathbf{R}_{t+1}\right)=\mathbf{1}_{K}$, with $\mathbf{b}=\operatorname{Var}\left[\mathbf{R}_{t+1}\right]^{-1}\left(1-v E\left(\mathbf{R}_{t+1}\right)\right)$, and $v=E(m)$ is related to the risk-free rate by $1+r_{f}=1 / E(m)$.

Test without market frictions. To derive a test statistic for the spanning hypothesis from Equation (9) we rearrange terms

$$
v E\left(\mathbf{r}_{t+1}\right)+\operatorname{Cov}\left[\mathbf{r}_{t+1}, \mathbf{R}_{t+1}\right] \operatorname{Var}\left[\mathbf{R}_{t+1}\right]^{-1}\left(1_{N}-v E\left(\mathbf{R}_{t+1}\right)\right)=\mathbf{0}_{N}
$$

and further simplifications (see e.g. DeRoon and Nijman (2001)) give

$$
\boldsymbol{\Lambda}(v)=v \mathbf{a}+\left(\mathbf{B} \mathbf{1}_{K}-\mathbf{1}_{N}\right)=\mathbf{0}_{N},
$$

where $\mathbf{a}$ and $\mathbf{B}$ can be found from the OLS regression:

$$
\mathbf{r}_{t+1}=\mathbf{a}+\mathbf{B R}_{\mathbf{t}+\mathbf{1}}+\varepsilon_{t+1}
$$

The classical Huberman and Kandel (1987) test for spanning can be performed by computing the Wald statistic:

$$
H K(v)=\boldsymbol{\Lambda}(v)^{\prime} \operatorname{Var}[\boldsymbol{\Lambda}(v)]^{-1} \boldsymbol{\Lambda}(v)
$$

We only test for one specific value, $v=1$, i.e. the inverse of the empirically observed risk-free interest rate. That is, in terms of Huberman and Kandel (1987), we test for 
"intersection" rather than spanning. Setting $v=1 /\left(1+r_{f}\right)$ means that we test the portfolio with the maximum available Sharpe ratio in the mean-variance space (see DeRoon and Nijman (2001)).

Relation to alpha. We can rewrite Equation (12) in terms of returns in excess of the risk-free rate (instead of gross returns):

$$
\mathbf{r}_{t+1}-r_{f} \mathbf{1}_{K}=\boldsymbol{\alpha}+\boldsymbol{\beta}\left(\mathbf{R}_{\mathbf{t}+\mathbf{1}}-r_{f} \mathbf{1}_{N}\right)+\varepsilon_{t+1}
$$

This expression is equivalent to the dynamic internal rate of return which we exploit to discount net present values of human capital contracts (see Equation (7)). It can be shown that the restriction that alphas are significantly different from zero is equivalent to the Huberman and Kandel coefficient restriction in Equation (11)

$$
\boldsymbol{\Lambda}(v)=v \mathbf{a}+\left(\mathbf{B} \mathbf{1}_{K}-\mathbf{1}_{N}\right)=\boldsymbol{\alpha}=\mathbf{0}_{N},
$$

when testing for intersection of the portfolio with the maximum Sharpe ratio. Thus, testing the significance of alphas, as we do for cash flows of human capital contracts, is equivalent to performing tests using the Huberman and Kandel test statistic, as is done in Palacios-Huerta (2003).

Test with market frictions. In the presence of short selling constraints, the equilibrium condition becomes an inequality (He and Modest (1995), Luttmer (1996)):

$$
E\left(m_{t+1} \mathbf{R}_{t+1}\right) \leq \mathbf{1}_{K}
$$

DeRoon, Nijman, and Werker (2001) show that the coefficient restrictions of Equation (11) now become inequalities as well:

$$
\boldsymbol{\Lambda}(v)=v \mathbf{a}+\left(\mathbf{B} \mathbf{1}_{K}-\mathbf{1}_{N}\right) \leq \mathbf{0}_{N}
$$


To test these inequalities, DeRoon, Nijman, and Werker (2001) propose the test statistic

$$
D N W(v)=\min _{\{\boldsymbol{\lambda} \leq \mathbf{0}\}}(\boldsymbol{\Lambda}(v)-\boldsymbol{\lambda})^{\prime} \operatorname{Var}[\boldsymbol{\Lambda}(v)]^{-1}(\boldsymbol{\Lambda}(v)-\boldsymbol{\lambda}),
$$

which offers the following intuition. A positive element of the $\mathrm{N}$ dimensional vector $\boldsymbol{\Lambda}(v)$ means that the investor should give a positive portfolio weight to the specific test asset. A negative element means that the investor should give a negative portfolio weight to the specific test asset. However, under short sales constraint, the latter is not possible and $\boldsymbol{\lambda}$ will account for this fact in the test statistic for spanning.

Test statistic distribution. Because our sample is relatively short, we do not want to rely on the asymptotic distributions of our test statistics. We use 1,000 bootstraps to derive the empirical distribution of all our test statistics. 


\section{References}

BeCKer, G. S. (1993): Human capital: A theoretical and empirical analysis with special reference to education. Chicago: University of Chicago Press.

Bekaert, G., And M. S. URias (1996): "Diversification, Integration and Emerging Market Closed-End Funds," Journal of Finance, 51, 835-869.

Campbell, J. Y. (1996): "Understanding Risk and Return," Journal of Political Economy, 104, 298-345.

Cochrane, J. H. (2005): Asset Pricing. Princeton University Press, New Jersey.

Council of the European Union (2009): "Council Conclusions of 12 May 2009 on a Strategic Framework for European Cooperation in Education and Training ('ET 2020'), 28.05.2009," http://eur-lex.europa.eu/LexUriServ/LexUriServ.do?uri= OJ : C: 2009:119:0002:0010:EN:PDF, [Available online; accessed 09.06.2012].

DeRoon, F. A., And T. E. Nijman (2001): "Testing for Mean-Variance Spanning: A Survey," Journal of Empirical Finance, 8, 111-155.

DeRoon, F. A., T. E. NiJman, And B. J. M. Werker (2001): "Testing for MeanVariance Spanning with Short Sales Constraints and Transaction Costs: The Case of Emerging Markets," Journal of Finance, 56, 721-742.

Driessen, J., T.-C. Lin, And L. Phalippou (2012): "A New Method to Estimate Risk and Return of Nontraded Assets from Cash Flows: The Case of Private Equity Funds," Journal of Financial and Quantitiative Analysis, 47, 511-535.

EILING, E. (2013): "Industry-Specific Human Capital, Idiosyncratic Risk, and the CrossSection of Expected Stock Returns," Journal of Finance, 68, 43-84.

Fama, E. F., And K. R. French (2010): "Luck versus Skill in Mutual Fund Returns," Journal of Finance, 65, 1915-1947. 
Fama, E. F., And G. W. Schwert (1977): "Human Capital and Capital Market Equilibrium," Journal of Financial Economics, 4, 95-125.

Friedman, M. (1955): The Role of Government in Education. Available as reprint at: http://www.schoolchoices.org/roo/fried1.htm.

Hansen, L. P., And R. Jagannathan (1991): "Implications of Security Market Data for Models of Dynamic Economies," Journal of Political Economy, 99, 225-262.

He, H., And D. M. Modest (1995): "Market Frictions and Consumption-Based Asset Pricing," Journal of Political Economy, 103, 94-117.

Huberman, G., And S. Kandel (1987): "Mean-Variance Spanning," Journal of Finance, $42,873-888$.

Jagannathan, R., And Z. WAng (1996): "The Conditional CAPM and the CrossSection of Expected Returns," Journal of Finance, 51, 3-53.

Lintner, J. (1965): "Security Prices Risk, and Maximal Gains from Diversification," Journal of Finance, 20, 587-615.

Ludwig, A., D. Krueger, And A. H. Boersch-Supan (2007): "Demographic Change, Relative Factor Prices, International Capital Flows, and Their Differential Effects on the Welfare of Generations," Working Paper 13185, National Bureau of Economic Research.

Lustig, H., S. van Nieuwerburgh, And A. Verdelhan (2013): "The WealthConsumption Ratio," Review of Asset Pricing Studies, forthcoming.

Luttmer, E. G. J. (1996): “Asset Pricing in Economies with Frictions," Econometrica, 64, 1439-1467.

OECD (2010): Education at a Glance. Paris: Organization for Economic Collaboration and Development. 
Palacios, M. (2004): Investing in Human Capital - A Capital Markets Approach to Student Funding. Cambridge University Press.

Palacios-Huerta, I. (1997): "The Pricing of Human Capital and Financial Assets," Working Paper.

(2003): “An Empirical Analysis of the Risk Properties of Human Capital Returns," American Economic Review, 93, 948-964.

Sharpe, W. F. (1964): "Capital Asset Prices: A Theory of Market Equilibrium under Conditions of Risk," Journal of Finance, 19, 425-442. 


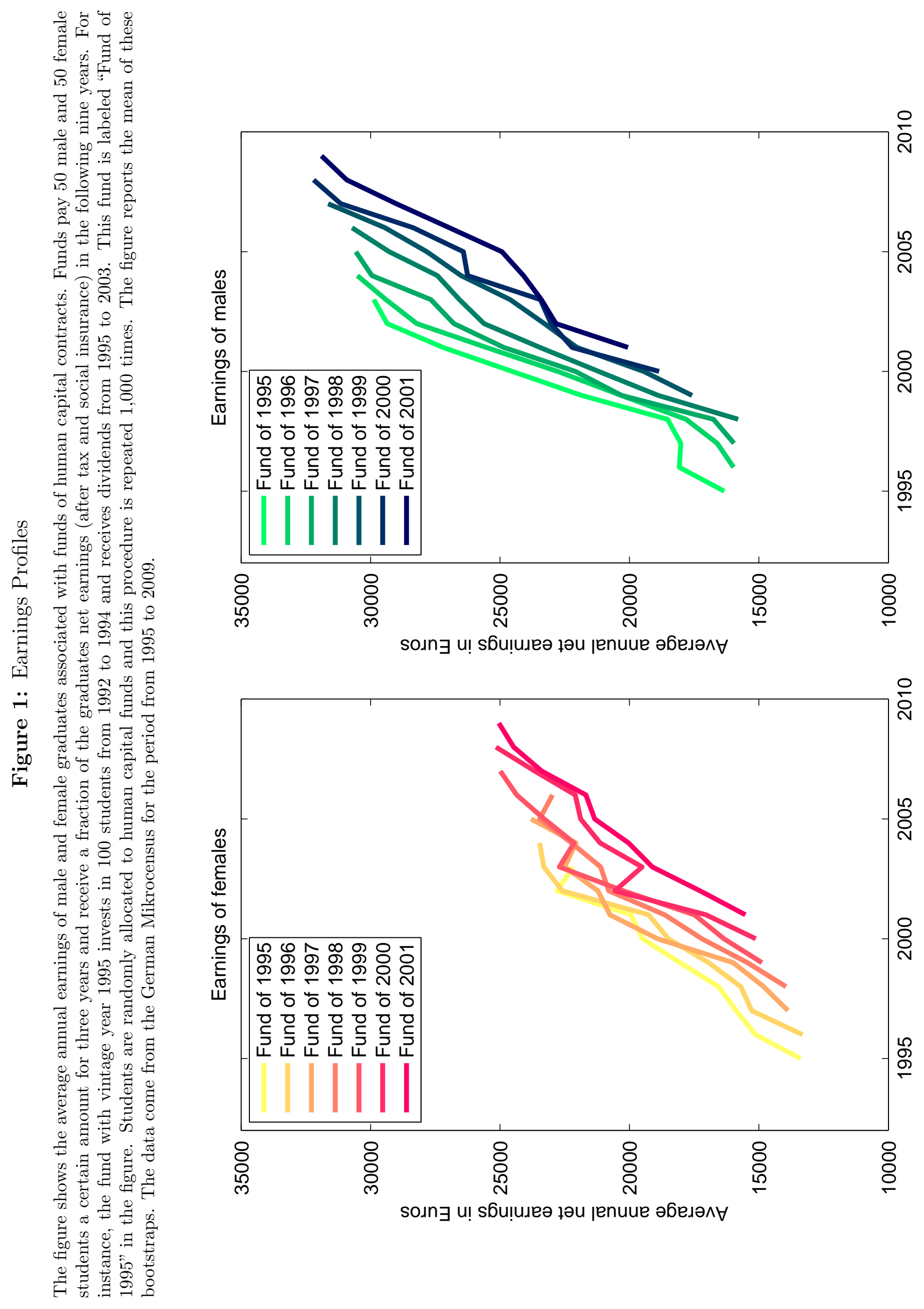




\section{Figure 2: Sensitivity of Risk Exposures}

The figure shows the contour map of the value function, i.e. the sum of net present values (as in Equation (6)), along the dimensions of the parameters to be estimated. Brighter areas in the figure correspond to a lower net present value. Human capital fund cash flows used for estimation correspond to the average cash flows of 1,000 bootstraps, as reported in Table $2(\theta=0.15)$. Estimation is based on univariate stock market risk in the upper part of the figure and on univariate bond market risk in the lower part of the figure.
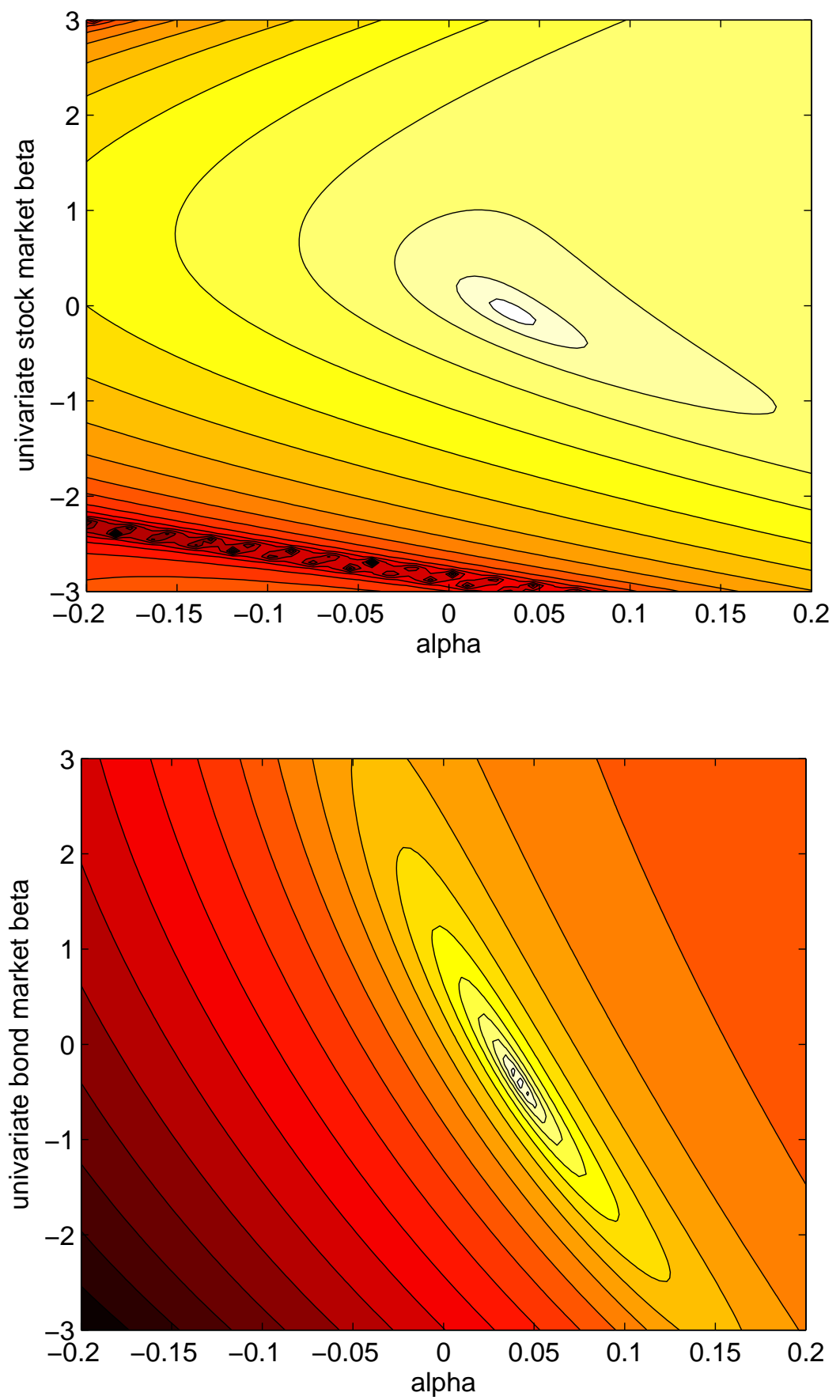
Figure 3: Share of Non-Performing Human Capital Contracts

The figure shows the share of non-performing human capital contracts within a given fund when the sample is not restricted to full-time employees, i.e. the share of graduates without any labor income. Funds pay 50 male and 50 female students 8.000 Euros (deflated by the 2009 consumer price index) each year for three years and receive a fraction of the graduates' net earnings (after tax and social insurance) during the following nine years. The fund's vintage year indicates the first year the fund receives repayments from the graduates. For instance, the fund with vintage year 1995 invests from 1992 to 1994 and receives dividends from 1995 to 2003. Students are randomly allocated to human capital funds. Results display the mean of 1,000 bootstraps. The data come from the German Mirkocensus for the period from 1995 to 2009.

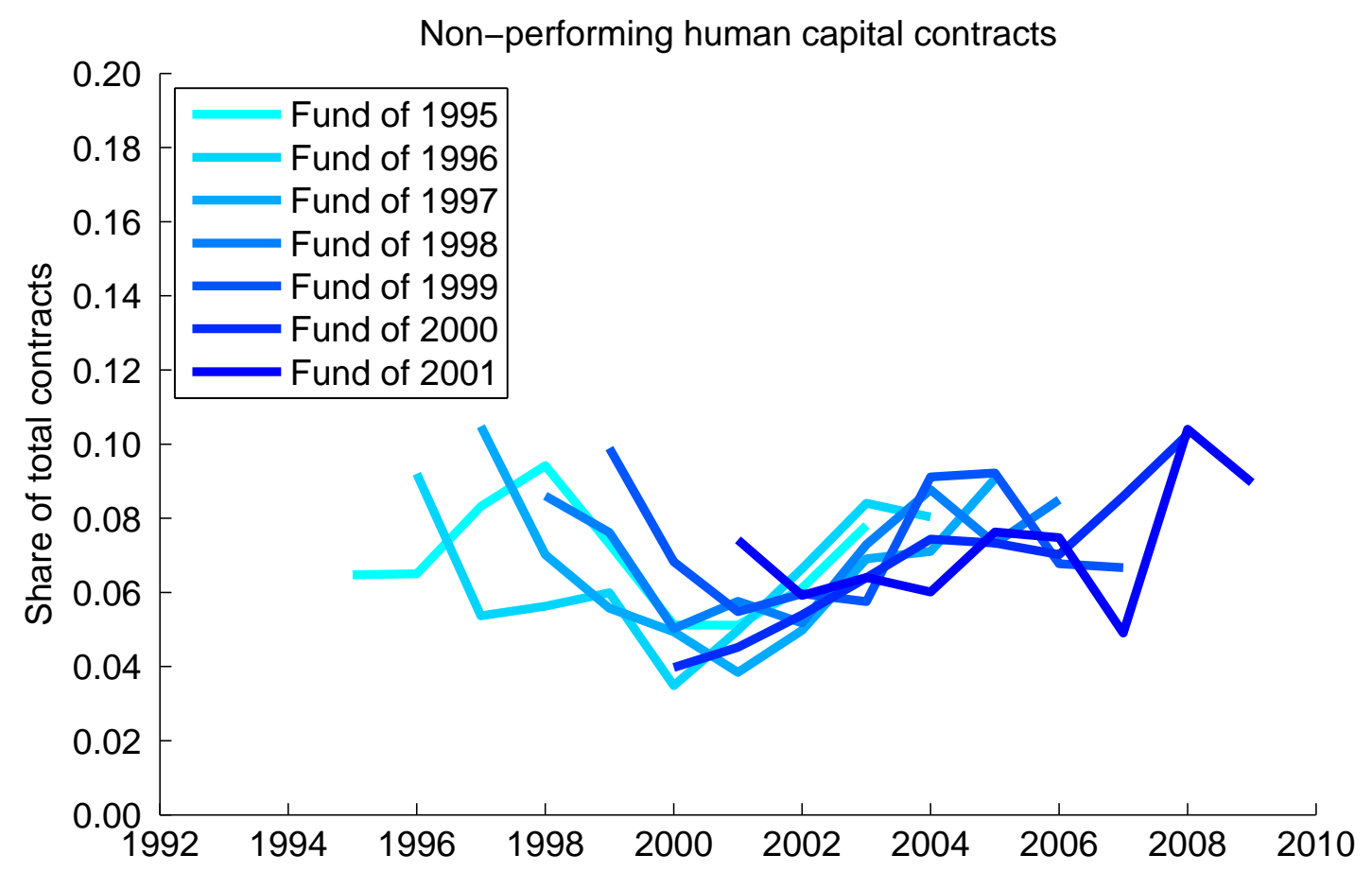




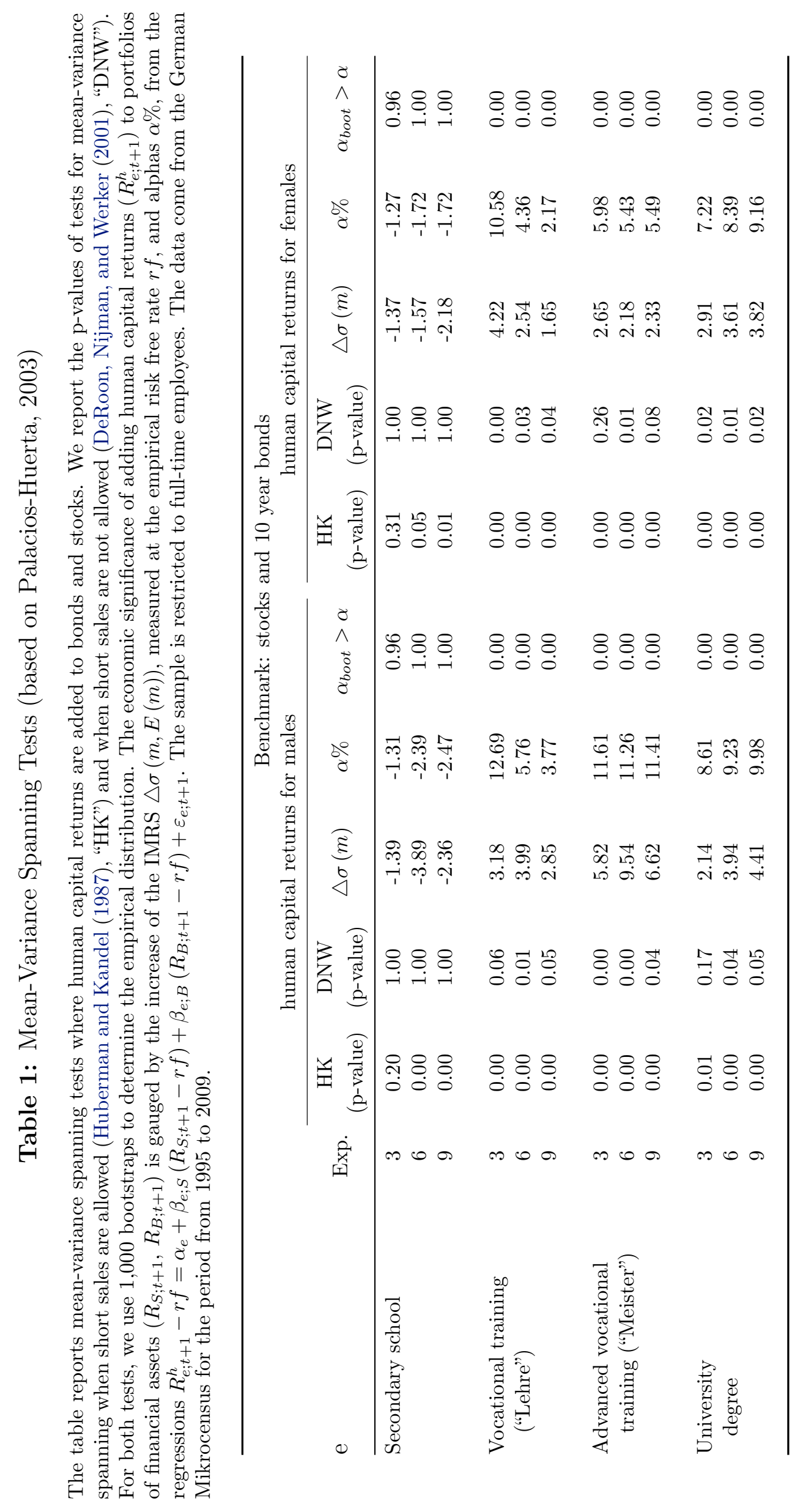


Table 2: Cash Flows of Human Capital Funds

The table reports average fund cash flows per student. Funds pay 50 male and 50 female students 8.000 Euros (deflated by the 2009 consumer price index) for three years and receive the fraction $\theta=0.15$ of the students' net earnings (after tax and social insurance) during the following nine years. The fund's vintage year indicates the first year the fund receives repayments from the students. For instance, the fund with vintage year 1995 invests from 1992 to 1994 and receives dividends from 1995 to 2003. Students are randomly allocated to human capital funds. The sample is restricted to full-time employees. Results display the mean of 1,000 bootstraps. The data come from the German Mikrocensus for the period from 1995 to 2009.

\begin{tabular}{|c|c|c|c|c|c|c|c|}
\hline \multirow[b]{3}{*}{$\begin{array}{l}\text { Payout } \\
\text { year }\end{array}$} & \multicolumn{7}{|c|}{ Fund cash flows per student (Euros) } \\
\hline & \multicolumn{7}{|c|}{ Vintage year } \\
\hline & 1995 & 1996 & 1997 & 1998 & 1999 & 2000 & 2001 \\
\hline 1992 & $-5,972$ & 0 & 0 & 0 & 0 & 0 & 0 \\
\hline 1993 & $-6,231$ & $-6,231$ & 0 & 0 & 0 & 0 & 0 \\
\hline 1994 & $-6,400$ & $-6,400$ & $-6,400$ & 0 & 0 & 0 & 0 \\
\hline 1995 & 2,339 & $-6,505$ & $-6,505$ & $-6,505$ & 0 & 0 & 0 \\
\hline 1996 & 2,393 & 2,181 & $-6,602$ & $-6,602$ & $-6,602$ & 0 & 0 \\
\hline 1997 & 2,455 & 2,392 & 2,280 & $-6,708$ & $-6,708$ & $-6,708$ & 0 \\
\hline 1998 & 2,611 & 2,436 & 2,411 & 2,510 & $-6,796$ & $-6,796$ & $-6,796$ \\
\hline 1999 & 3,083 & 3,040 & 2,614 & 2,622 & 2,189 & $-6,829$ & $-6,829$ \\
\hline 2000 & 3,337 & 3,022 & 2,968 & 2,880 & 2,763 & 2,477 & $-6,917$ \\
\hline 2001 & 3,415 & 3,527 & 3,470 & 3,132 & 2,979 & 2,806 & 2,601 \\
\hline 2002 & 3,820 & 3,661 & 3,623 & 3,568 & 3,313 & 3,313 & 2,958 \\
\hline 2003 & 3,677 & 3,859 & 3,737 & 3,484 & 3,527 & 3,412 & 3,169 \\
\hline 2004 & 0 & 4,268 & 3,862 & 3,526 & 3,520 & 3,637 & 3,056 \\
\hline 2005 & 0 & 0 & 3,863 & 3,796 & 4,155 & 3,743 & 3,270 \\
\hline 2006 & 0 & 0 & 0 & 4,068 & 4,057 & 4,008 & 3,709 \\
\hline 2007 & 0 & 0 & 0 & 0 & 4,588 & 3,944 & 3,944 \\
\hline 2008 & 0 & 0 & 0 & 0 & 0 & 4,417 & 4,300 \\
\hline 2009 & 0 & 0 & 0 & 0 & 0 & 0 & 4,414 \\
\hline
\end{tabular}


Table 3: Return and Risk of Human Capital Contracts

The table reports the internal rate of return (IRR), the abnormal return $(\alpha)$ and financial market risk exposures $(\beta)$ of funds of human capital contracts. Funds pay 50 male and 50 female students 8.000 Euros (deflated by the 2009 consumer price index) for three years and receive a fraction $\theta$ of the students' net earnings (after tax and social insurance) in the following nine years. Students are randomly allocated to human capital funds. In Panel A, the sample is restricted to full-time employees. The sample used in Panel B also includes unemployed individuals, individuals on parental leave, individuals dependat on family or state support and part-time workers. Abnormal returns and risk exposures to stocks and bonds are calculated from human capital fund cash flows using a GMM estimator proposed by Driessen, Lin, and Phalippou (2012). The procedure is repeated 1,000 times. The mean and the $95 \%$ confidence interval of the estimated return and risk characteristics are displayed. The data come from the German Mikrocensus for the period from 1995 to 2009.

\begin{tabular}{|c|c|c|c|c|c|}
\hline & \multicolumn{5}{|c|}{ Share of net earnings repaid to the fund $(\theta)$} \\
\hline & 0.100 & 0.125 & 0.150 & 0.175 & 0.200 \\
\hline \multicolumn{6}{|c|}{ Panel A: Full-time workers } \\
\hline \multirow{4}{*}{$\begin{array}{l}\text { Mean IRR } \\
95 \% \text { conf. }\end{array}$} & \multicolumn{5}{|c|}{ internal rate of return } \\
\hline & 0.07 & 3.66 & 6.78 & 9.57 & 12.10 \\
\hline & {$\left[\begin{array}{ll}-0.11 & 0.25\end{array}\right]$} & {$\left[\begin{array}{ll}3.47 & 3.85\end{array}\right]$} & {$\left[\begin{array}{ll}6.58 & 6.98\end{array}\right]$} & {$\left[\begin{array}{ll}9.36 & 9.77\end{array}\right]$} & {$\left[\begin{array}{ll}11.88 & 12.31\end{array}\right]$} \\
\hline & \multicolumn{5}{|c|}{ abnormal return and risk exposures } \\
\hline Mean $\alpha$ & -3.23 & 0.43 & 3.62 & 6.48 & 9.08 \\
\hline $95 \%$ conf. & {$\left[\begin{array}{ll}-4.14 & -2.29\end{array}\right]$} & {$\left[\begin{array}{ll}-0.49 & 1.32\end{array}\right]$} & {$\left[\begin{array}{ll}2.70 & 4.50\end{array}\right]$} & {$\left[\begin{array}{ll}5.56 & 7.36\end{array}\right]$} & {$\left[\begin{array}{ll}8.17 & 9.99\end{array}\right]$} \\
\hline Mean $\beta_{\text {Stocks }}$ & -0.04 & -0.04 & -0.05 & -0.05 & -0.06 \\
\hline $95 \%$ conf. & {$\left[\begin{array}{ll}-0.12 & 0.05\end{array}\right]$} & {$\left[\begin{array}{ll}-0.13 & 0.04\end{array}\right]$} & {$\left[\begin{array}{ll}-0.13 & 0.03\end{array}\right]$} & {$\left[\begin{array}{ll}-0.14 & 0.03\end{array}\right]$} & {$\left[\begin{array}{ll}-0.14 & 0.02\end{array}\right]$} \\
\hline \multirow{2}{*}{$\begin{array}{l}\text { Mean } \beta_{\text {Bonds }} \\
95 \% \text { conf. }\end{array}$} & -0.08 & -0.09 & -0.09 & -0.09 & -0.10 \\
\hline & {$\left[\begin{array}{ll}-0.55 & 0.39\end{array}\right]$} & {$\left[\begin{array}{ll}-0.53 & 0.38\end{array}\right]$} & {$\left[\begin{array}{ll}-0.53 & 0.38\end{array}\right]$} & {$\left[\begin{array}{ll}-0.52 & 0.37\end{array}\right]$} & {$\left[\begin{array}{ll}-0.52 & 0.35\end{array}\right]$} \\
\hline \multicolumn{6}{|c|}{ Panel B: All (including non-employed and part-time workers) } \\
\hline \multirow{4}{*}{$\begin{array}{l}\text { Mean IRR } \\
95 \% \text { conf. }\end{array}$} & \multicolumn{5}{|c|}{ internal rate of return } \\
\hline & -1.61 & 1.87 & 4.90 & 7.60 & 10.05 \\
\hline & {$\left[\begin{array}{ll}-1.84 & -1.39\end{array}\right]$} & {$\left[\begin{array}{ll}1.63 & 2.10\end{array}\right]$} & {$[4.64$} & {$[7.33$} & {$\left[\begin{array}{ll}9.77 & 10.32\end{array}\right]$} \\
\hline & & abnormal & return and risk & xposures & \\
\hline Mean $\alpha$ & -5.12 & -1.54 & 1.57 & 4.36 & 6.89 \\
\hline $95 \%$ conf. & {$\left[\begin{array}{ll}-6.16 & -3.98\end{array}\right]$} & {$\left[\begin{array}{ll}-2.56 & -0.43\end{array}\right]$} & {$\left[\begin{array}{ll}0.54 & 2.70\end{array}\right]$} & {$\left[\begin{array}{ll}3.31 & 5.46\end{array}\right]$} & {$\left[\begin{array}{ll}5.84 & 7.99\end{array}\right]$} \\
\hline Mean $\beta_{\text {Stocks }}$ & -0.03 & -0.04 & -0.04 & -0.05 & -0.05 \\
\hline $95 \%$ conf. & {$\left[\begin{array}{ll}-0.14 & 0.07\end{array}\right]$} & {$\left[\begin{array}{ll}-0.14 & 0.06\end{array}\right]$} & {$\left[\begin{array}{ll}-0.14 & 0.06\end{array}\right]$} & {$\left[\begin{array}{ll}-0.15 & 0.05\end{array}\right]$} & {$\left[\begin{array}{ll}-0.15 & 0.04\end{array}\right]$} \\
\hline Mean $\beta_{\text {Bonds }}$ & -0.02 & -0.04 & -0.05 & -0.06 & -0.07 \\
\hline $95 \%$ conf. & {$[-0.60$} & {$[-0.61$} & {$\left[\begin{array}{ll}-0.60 & 0.50\end{array}\right]$} & {$[-0.60$} & {$[-0.61$} \\
\hline
\end{tabular}


Table 4: Robustness - Full-time

The table reports the abnormal return $(\alpha)$ and financial market risk exposures $(\beta)$ of funds of human capital contracts. In each panel one of the human capital contract characteristics is changed as compared with the baseline contract. In Panel A, repayments are capped such that graduates have an income of at least 1.300 Euros per month (deflated by the 2009 consumer price index) after paying the fund. In Panel $\mathrm{B}$, funds invest in only 50 students, thereby increasing idiosyncratic risk. In Panel C, funds invest in 150 students, thereby reducing idiosyncratic risk. In Panel $\mathrm{C}$, funds collect repayments for only 8 years after graduation. In Panel D, funds collect repayments for as long as 10 years after graduation. The sample is restricted to full-time employees.

Share of net earnings repaid to the fund $(\theta)$
0.100
0.125
0.150
0.175
0.200

Panel A: Repayments are capped (students have at least 1.300 Euros per month after paying to fund)

\begin{tabular}{|c|c|c|c|c|c|}
\hline Mean $\alpha$ & -4.10 & -0.84 & 1.90 & 4.56 & 7.04 \\
\hline $95 \%$ conf. & {$[-5.24$} & {$[-2.01$} & {$[0.72$} & {$[3.35$} & {$[5.75$} \\
\hline Mean $\beta_{\text {Stocks }}$ & -0.05 & -0.06 & -0.09 & -0.11 & -0.11 \\
\hline $95 \%$ conf. & {$\left[\begin{array}{lr}-0.16 & 0.06\end{array}\right]$} & {$[-0.17$} & {$[-0.21$} & {$[-0.23$} & {$[-0.24$} \\
\hline Mean $\beta_{\text {Bonds }}$ & -0.17 & -0.12 & $0^{-0.01}$ & -0.03 & -0.09 \\
\hline $95 \%$ conf. & {$[-0.75$} & {$[-0.73$} & {$[-0.63$} & {$[-0.65$} & {$[-0.73$} \\
\hline
\end{tabular}

Panel B: More idiosyncratic risk (funds with 50 students)

\begin{tabular}{|c|c|c|c|c|c|}
\hline Mean $\alpha$ & -3.25 & 0.41 & 3.60 & 6.46 & 9.06 \\
\hline $95 \%$ conf. & {$\left[\begin{array}{ll}-4.43 & -1.98\end{array}\right]$} & {$[-0.78$} & {$[2.42$} & {$[5.27$} & $10.35]$ \\
\hline Mean $\beta_{\text {Stocks }}$ & -0.04 & -0.05 & -0.05 & -0.06 & -0.06 \\
\hline $95 \%$ conf. & {$\left[\begin{array}{ll}-0.16 & 0.08\end{array}\right]$} & {$\left[\begin{array}{ll}-0.17 & 0.07\end{array}\right]$} & {$[-0.17$} & {$[-0.18$} & {$[-0.19$} \\
\hline Mean $\beta_{\text {Bonds }}$ & -0.06 & -0.07 & -0.07 & -0.07 & -0.08 \\
\hline $95 \%$ conf. & {$[-0.69$} & {$[-0.70$} & {$[-0.69$} & {$[-0.67$} & {$[-0.67$} \\
\hline
\end{tabular}

Panel C: Less idiosyncratic risk (funds with 150 students)

\begin{tabular}{|c|c|c|c|c|c|}
\hline Mean $\alpha$ & -3.25 & 0.41 & 3.60 & 6.46 & 9.06 \\
\hline $95 \%$ conf. & $-2.49]$ & {$[-0.29$} & {$[2.89$} & {$[5.73$} & {$[8.31$} \\
\hline Mean $\beta_{\text {Stocks }}$ & -0.04 & -0.04 & -0.05 & -0.05 & -0.06 \\
\hline $95 \%$ conf. & {$[-0.12$} & {$[-0.12$} & {$\left[\begin{array}{ll}-0.12 & 0.02\end{array}\right]$} & {$\left[\begin{array}{ll}-0.13 & 0.01\end{array}\right]$} & {$\left[\begin{array}{ll}-0.13 & 0.01\end{array}\right]$} \\
\hline Mean $\beta_{\text {Bonds }}$ & -0.08 & -0.08 & -0.09 & -0.09 & -0.09 \\
\hline $95 \%$ conf. & {$[-0.47$} & {$[-0.46$} & {$[-0.46$} & {$[-0.46$} & {$[-0.46$} \\
\hline
\end{tabular}

Panel D: Short duration funds (8 repayment years)

\begin{tabular}{|c|c|c|c|c|c|}
\hline Mean $\alpha$ & -5.42 & -1.63 & 1.68 & 4.64 & 7.33 \\
\hline $95 \%$ conf. & {$\left[\begin{array}{ll}-6.68 & -4.01\end{array}\right]$} & {$\left[\begin{array}{ll}-2.84 & -0.29\end{array}\right]$} & {$\left[\begin{array}{ll}0.50 & 2.95\end{array}\right]$} & {$[3.49$} & {$[6.21$} \\
\hline Mean $\beta_{\text {Stocks }}$ & -0.00 & -0.01 & -0.02 & -0.02 & -0.03 \\
\hline $95 \%$ conf. & {$\left[\begin{array}{ll}-0.10 & 0.08\end{array}\right]$} & {$[-0.10$} & {$[-0.10$} & {$[-0.10$} & {$[-0.11$} \\
\hline Mean $\beta_{\text {Bonds }}$ & -0.26 & -0.25 & -0.24 & -0.23 & -0.23 \\
\hline $95 \%$ conf. & {$[-0.86$} & {$[-0.81$} & {$[-0.78$} & {$[-0.75$} & {$[-0.73$} \\
\hline \multicolumn{6}{|c|}{ Panel E: Long duration funds (10 repayment years) } \\
\hline Mea & -1.33 & 2.18 & 5.25 & 8.01 & 10.52 \\
\hline $95 \%$ conf. & {$\left[\begin{array}{ll}-2.03 & -0.57\end{array}\right]$} & {$\left[\begin{array}{ll}1.45 & 2.93\end{array}\right]$} & {$[4.50$} & {$[7.23$} & $11.37]$ \\
\hline Mean $\beta_{\text {Stocks }}$ & -0.04 & -0.05 & -0.06 & -0.07 & -0.07 \\
\hline $95 \%$ conf. & {$[-0.15$} & {$[-0.15$} & {$[-0.16$} & {$[-0.16$} & {$[-0.17$} \\
\hline Mean $\beta_{\text {Bonds }}$ & -0.05 & -0.05 & -0.05 & -0.05 & -0.05 \\
\hline $95 \%$ conf. & {$[-0.52$} & {$[-0.50$} & {$[-0.49$} & {$[-0.48$} & {$[-0.48$} \\
\hline
\end{tabular}


Table 5: Robustness - All

The table reports the abnormal return $(\alpha)$ and financial market risk exposures $(\beta)$ of funds of human capital contracts. As inTable 4, in each panel one of the human capital contract characteristics is changed but the sample is not restricted to full-time workers and also includes unemployed and part-time workers.

Share of net earnings repaid to the fund $(\theta)$

$\begin{array}{lllll}0.100 & 0.125 & 0.150 & 0.175 & 0.200\end{array}$

Panel A: Repayments are capped (students have at least 1.300 Euros per month after paying to fund)

\begin{tabular}{|c|c|c|c|c|c|}
\hline Mean $\alpha$ & -6.32 & -3.17 & -0.54 & 2.01 & 4.41 \\
\hline $95 \%$ conf. & {$[-7.54$} & {$[-4.46$} & {$[-1.83$} & {$[0.70$} & {$[3.04$} \\
\hline Mean $\beta_{\text {Stocks }}$ & -0.05 & -0.06 & -0.09 & -0.10 & -0.11 \\
\hline $95 \%$ conf. & {$[-0.20$} & {$[-0.21$} & {$[-0.24$} & {$[-0.25$} & {$[-0.26$} \\
\hline Mean $\beta_{\text {Bonds }}$ & -0.07 & -0.02 & 0.07 & 0.05 & -0.01 \\
\hline $95 \%$ conf. & {$[-0.75$} & {$[-0.73$} & {$[-0.63$} & {$[-0.67$} & {$[-0.76$} \\
\hline
\end{tabular}

Panel B: More idiosyncratic risk (funds with 50 students)

\begin{tabular}{|c|c|c|c|c|c|}
\hline Mean $\alpha$ & -5.08 & -1.51 & 1.60 & 4.38 & 6.91 \\
\hline $95 \%$ conf. & {$[-6.50$} & {$[-2.93$} & {$[0.18$} & {$[2.95$} & {$[5.49$} \\
\hline Mean $\beta_{\text {Stocks }}$ & -0.03 & -0.04 & -0.04 & -0.05 & -0.05 \\
\hline $95 \%$ conf. & {$\left[\begin{array}{ll}-0.18 & 0.12\end{array}\right]$} & {$[-0.18$} & {$[-0.19$} & {$[-0.19$} & {$[-0.19$} \\
\hline Mean $\beta_{\text {Bonds }}$ & -0.03 & -0.04 & -0.05 & -0.06 & -0.07 \\
\hline $95 \%$ conf. & {$[-0.82$} & {$[-0.82$} & {$[-0.83$} & {$[-0.80$} & {$[-0.81$} \\
\hline
\end{tabular}

Panel C: Less idiosyncratic risk (funds with 150 students)

\begin{tabular}{|c|c|c|c|c|c|}
\hline Mean $\alpha$ & -5.12 & -1.54 & 1.58 & 4.36 & 6.89 \\
\hline $95 \%$ conf. & {$[-5.97$} & {$[-2.40$} & {$[0.73$} & {$[3.50$} & {$[6.00$} \\
\hline Mean $\beta_{\text {Stocks }}$ & -0.03 & -0.04 & -0.04 & -0.05 & -0.05 \\
\hline $95 \%$ conf. & {$\left[\begin{array}{ll}-0.12 & 0.05\end{array}\right]$} & {$[-0.12$} & {$[-0.13$} & {$[-0.13$} & {$[-0.13$} \\
\hline Mean $\beta_{\text {Bonds }}$ & -0.02 & -0.03 & -0.05 & -0.06 & -0.07 \\
\hline $95 \%$ conf. & {$[-0.48$} & {$[-0.49$} & {$[-0.49$} & {$[-0.50$} & {$[-0.51$} \\
\hline
\end{tabular}

Panel D: Short duration funds (8 repayment years)

\begin{tabular}{|c|c|c|c|c|c|}
\hline \multirow{6}{*}{$\begin{array}{l}\text { Mean } \alpha \\
95 \% \text { conf. } \\
\text { Mean } \beta_{\text {Stocks }} \\
95 \% \text { conf. } \\
\text { Mean } \beta_{\text {Bonds }} \\
\text { 95\% conf. }\end{array}$} & -6.95 & -3.29 & -0.10 & 2.75 & 5.35 \\
\hline & \multirow{2}{*}{$\begin{array}{c}-8.50^{-5.90} \\
0.04^{-5.19}\end{array}$} & \multirow{2}{*}{ 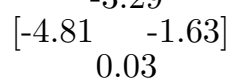 } & \multirow{2}{*}{$\begin{array}{cc}-1.55 & 1.46] \\
0.02 & \end{array}$} & \multirow{2}{*}{$\begin{array}{c}1.355_{0.01}^{4.23]} \\
\end{array}$} & \multirow{2}{*}[\begin{array}{cc}{3.96}&{6.84}\\
{0.00}\end{array}]{} \\
\hline & & & & & \\
\hline & {$\left[\begin{array}{ll}-0.07 & 0.14\end{array}\right]$} & {$\left[\begin{array}{ll}-0.08 & 0.12\end{array}\right]$} & {$\left[\begin{array}{ll}-0.08 & 0.11\end{array}\right]$} & {$\left[\begin{array}{ll}-0.09 & 0.10\end{array}\right]$} & {$\left[\begin{array}{ll}-0.09 & 0.09\end{array}\right]$} \\
\hline & -0.40 & -0.38 & -0.36 & -0.35 & -0.35 \\
\hline & {$\left[\begin{array}{ll}-1.13 & 0.29\end{array}\right]$} & {$\left[\begin{array}{ll}-1.05 & 0.26\end{array}\right]$} & {$\left[\begin{array}{ll}-1.00 & 0.27\end{array}\right]$} & {$\left[\begin{array}{ll}-0.96 & 0.27\end{array}\right]$} & {$\left[\begin{array}{ll}-0.94 & 0.26\end{array}\right]$} \\
\hline \multicolumn{6}{|c|}{ Panel E: Long duration funds (10 repayment years) } \\
\hline Mean $\alpha$ & -3.20 & 0.22 & 3.21 & 5.90 & 8.34 \\
\hline $95 \%$ conf. & {$\left[\begin{array}{ll}-4.06 & -2.25\end{array}\right]$} & {$\left[\begin{array}{ll}-0.65 & 1.20\end{array}\right]$} & {$\left[\begin{array}{ll}2.30 & 4.21\end{array}\right]$} & {$\left[\begin{array}{ll}4.96 & 6.93\end{array}\right]$} & {$\left[\begin{array}{ll}7.39 & 9.42\end{array}\right]$} \\
\hline Mean $\beta_{\text {Stocks }}$ & -0.05 & -0.06 & -0.06 & -0.07 & -0.08 \\
\hline $95 \%$ conf. & {$\left[\begin{array}{ll}-0.18 & 0.08\end{array}\right]$} & {$\left[\begin{array}{ll}-0.19 & 0.07\end{array}\right]$} & {$\left[\begin{array}{ll}-0.20 & 0.06\end{array}\right]$} & {$\left[\begin{array}{ll}-0.20 & 0.06\end{array}\right]$} & {$\left[\begin{array}{ll}-0.21 & 0.05\end{array}\right]$} \\
\hline Mean $\beta_{\text {Bonds }}$ & 0.04 & 0.03 & 0.02 & 0.02 & 0.01 \\
\hline $95 \%$ conf. & {$[-0.50$} & {$[-0.50$} & {$[-0.49$} & $0.52]$ & {$[-0.51$} \\
\hline
\end{tabular}

